Technical Papers

FBG Embedded 현장 조립형 커넥터의 자동 정렬 및 단면 자동 검사 시스템 개발

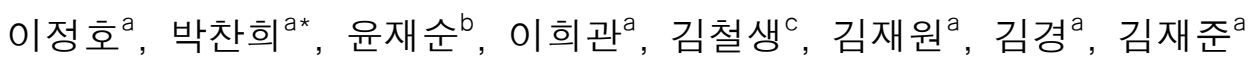

\title{
Development of Automatic Alignment Height and Cross-section Inspection System for Fiber Bragg Grating Embedded Field Assembly Connector
}

\author{
Jung-Ho Lee ${ }^{\mathrm{a}}$, Chan-Hee Park ${ }^{\mathrm{a}^{*}}$, Jae-Soon Yoon ${ }^{\mathrm{b}}$, Hee-Kwan Lee ${ }^{\mathrm{a}}$, Cheol-Sang Kim ${ }^{\mathrm{c}}$, Jae-Won Kim ${ }^{\mathrm{a}}$, \\ Kyung Kim ${ }^{\text {a }}$ Jae-Jun Kim ${ }^{\text {a }}$ \\ ${ }^{a}$ Chonbuk National University Automobile-part \& Mold Technology Innovation Center, \#67, Yu-Sang-ro, Dukjin-city, \\ Jeollabuk-do, Republic of Korea \\ ${ }^{b}$ Luxcom, 204,1-dong, Gwangjutechnopark, 958-3 Daechon-dong, Buk-gu, Gwangju Metropolitan city, Republic of Korea \\ c ChonBuk National University, Mechanical design engineering, Keum-Am dong, Dukjij-ku, Jeollabuk-do, Republic of Korea
}

\begin{tabular}{lrll}
\multicolumn{4}{l}{ ARTICLE INFO } \\
\hline \multicolumn{2}{l}{ Article history: } & & \\
Received & 18 & October & 2013 \\
Revised & 20 & December & 2013 \\
Accepted & 12 & February & 2014 \\
\hline
\end{tabular}

Keywords:

FTTH (Fiber to the home)

Ferrule

FBG (Fiber Bragg grating)

Machine vision

Inspection

\begin{abstract}
Recently, in order to reduce the time required to replace an optical jumper cord, many researchers are using a field-installable connector and applying the ferrule polishing method, ferrule mechanical contact method, or ferrule fusion contact method. However, the process of arranging the length of the optical fiber, i.e., inserting the optical fiber into the ferrule by hand and checking its cross section, takes $60 \%$ of the time required for the entire process, which increasesthe overall cost. Therefore, in order to make this task more cost-effective, we will develop an automated inspection system with automatic cross-sectional arrangement of a field-installable connector. This system will be able to decrease the failure rate from $10 \%$ to $2 \%$ compared with the conventional method when cutting the optical fiber inserted into the ferrule. It will also improve the productivity by decreasing the test time by $28 \%$ compared with the conventional method. Our studies showed that it was possible to reduce the production costs and improve the quality of a field-installableconnector, and we expect it to dominate the market.
\end{abstract}

\section{1. 서 론}

초고속 통신망은 대용량화 및 전광섬유(All Optical Fiber) 망으 로의 변화를 보이고 있으며 이와 더불어 통신서비스의 경쟁으로 고품질, 고안전성의 요구가 더욱 높아지고 있는 현실이다. 이에 따 라서 차세대 광가입자망구조인 FTTH (Fiber to the home)와 같 은 고속, 대용량의 서비스를 이용하고자 하는 고객들에게 있어서
항시적인 작동을 유지하는 것이 핵심적인 이슈가 되고 있다. 기존 의 광통신연결인 광점퍼코드를 활용한 융합접촉방법은 작업의 장 시간 소요, 광점퍼코드의 여러 정리 작업의 필요성, 종단에 부착된 광커넥터의 특성 저 하시 교체작업의 어려움이 있다 ${ }^{[1]}$. 이러한 문 제점을 해결하기 위하여 최근에는 페롤 연마법, 페롤(Ferrule)내 기계식접촉법, 페롤내 융착접속법등이 적용된 현장조립형 커넥터 를 이용하면 FTTH모뎀의 공간적 활용성 증대와 구축현장에서의

* Corresponding author. Tel.: +82-63-219-0320

Fax: +82-63-219-0311

E-mail address: chpark@camtic.or.kr (Chan-Hee Park). 
신속한 조립으로 광선로 구축 비용 및 시간 등의 절약 이 가능하다 ${ }^{[2]}$. 하지만 FBG (Fiber Bragg Grating) Embedded 현장 조립형 커넥터의 경우 페롤에 삽입된 광파이버의 단면 상태에 따라 제품의 신뢰도가 결정되며, 페롤에 삽입된 광파이버의 길이를 정렬하고 단 면을 수작업으로 검사하는 공정이 전체 생산 공정 시간의 $60 \%$ 가 소요되기 때문에 생산되는 현장 조립형 FTTH의 커넥터의 생산 단가는 비교적 높은 편이다. 따라서 페롤에 삽입된 광파이버의 길 이 정렬 및 단면 검사를 대처할 수 있는 시스템 개발이 필요하며, 실시간 검사가 가능한 머신비전검사(Machine Vision Inspection) 시스템이 가장 효과적이다. 머신비전 검사 시스템은 1970년대 말 인간의 시각 기능에 대한 과학적 설명을 시도 하면서 시작되었고, 그 응용에 있어서도 다양한 공정에 적용되었다 ${ }^{[3-4]}$. 예를 들면 이차 원 영상으로부터 추출된 경계선과 꼭지점등의 영상 특징(Image Feature)을 이용하여 제품의 양, 불량을 판단하거나 부품의 위치와 종류를 자동으로 인식하는 영상인식기술들이 개발되었다 ${ }^{[5]}$. 실제 머신비전이 적용된 사례로는 Tucit, J, D. 등이 머신비전을 이용한 카시트 쿠션 프레임 검사 시스템을 개발 하였으며 ${ }^{[6]}$, Jin-Young $\mathrm{Kim}$ 등은 원형 단면 부품 조립단계에서 비전 기반 부품 형상 및 상대 오차를 측정하였다 ${ }^{[7]}$. 또한 Jin-seok Park 등은 스크류 볼트 형상 검사를 위한 머신 비전 시스템을 개발하였으며 ${ }^{[8-9]}$, Young Jo Choi 등은 머신비전 시스템을 이용한 마이크로 드릴 마멸의 상 태 감시 연구를 하였다 ${ }^{[10]}$. 그러나 선행되었던 많은 연구가 대부분 은 금속 부품의 2차원 형상을 획득 한 뒤, Edge detection 후에 Edge 의 길이를 계산하는 내용이 대부분 이었으며, 광파이버의 단 면을 검사 하는 연구는 없었다. 따라서 본 연구에서는 제품의 생산 단가를 줄이고 제품의 신뢰도를 높이기 위하여 영상시스템을 이용 한 단면 검사 시스템 개발과 이에 따른 성능 평가(시험)에 대하여 제시하고자 한다.

\section{2. 본 론}

\section{1 정렬 및 검사 시스템 구성}

기존에는 페롤에 삽입된 광파이버의 높이 정렬을 수작업으로 진 행 하였다. 페롤에 에폭시와 광파이버를 넣고 경화 시킨 후, 광파이 버를 절단하여 페롤에 삽입된 높이를 관리하고, 한 개씩 현미경에 삽입하여 광파이버의 단면을 검사하였다. 이때 삽입된 광파이버의 지름은 약 $125 \mu \mathrm{m}$ 이므로 물리적인 충격에 매우 취약하다. 검사 진행시 수작업 진행으로 광파이버에 손상을 미칠 수 있어 검사 전 에 깨지거나 부러지는 경우가 많이 발생하였다. 그로 인하여 불량 제품이 많이 발생하고, 페롤에 광파이버를 삽입하고 경화한 상태이 므로 페롤 에서 광파이버를 분리할 수 없어 같이 불량 처리를 할 수 밖에 없었다. 해당 연구에서는 불량 처리 시에 버려지는 페롤을

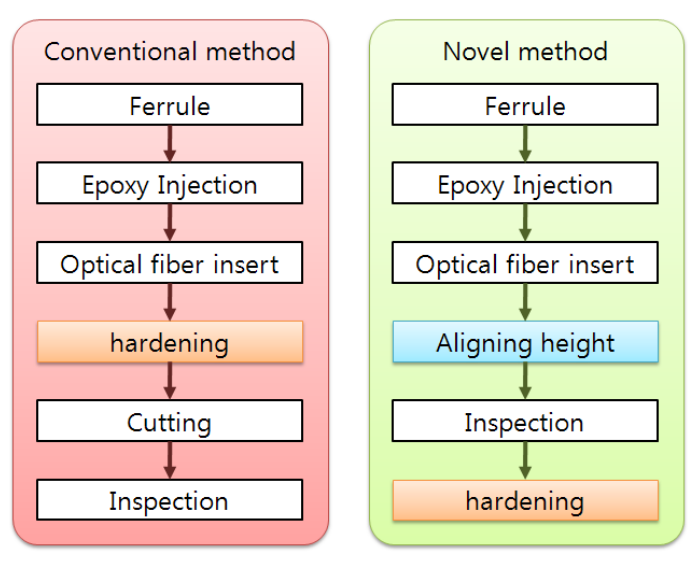

Fig. 1 Comparison of optical fiber inspection method

줄이고, 생산 속도를 향상시키기 위하여 자동 정렬 및 검사 시스템 을 개발 적용 하였다.

생산 공정 개선은 Fig. 1 과 같으며 경화 공정을 마지막 단계로 변경하였다. 이로 인하여 광파이버 검사 후 불량 제품에 대해서는 광파이버만 제거하면 페롤 재사용이 가능하므로 가능으로 원가 절 감 효과를 보였다.

광파이버 검사 시스템은 자동 정렬 시스템과 검사 시스템으로 구분된다. 자동 정렬 시스템 에서는 페롤에 삽입된 광파이버의 높 이를 정렬 하고, 검사 시스템에서는 삽입된 광파이버의 단면을 $\mathrm{CCD}$ 카메라를 이용하여 이미지 수집 후 영상처리를 통한 양품과 불량 여부를 판단한다.

\section{2 정렬 및 검사 시스템 기구 설계}

광파이버 자동 높이 정렬 및 검사 시스템은 Fig. 2 와 같이 4 개의 직교 로봇과 $\mathrm{CCD}$ 카메라, 집중광선(Spot Light), 고배율 렌즈로 구성된다. 2 개의 직교 로봇은 X-Y축 Stage를 구성하여 자동 정렬 과 검사 진행이 가능 하도록 정렬 Stage를 이동 시킨다. 나머지 2 개의 직교 로봇은 수직으로 세워 하나는 자동 정렬 장치, 나머지 하나는 $\mathrm{CCD}$ 카메라의 WD (Working Distance)조절을 통하여 오토포커싱이 가능한 로봇으로 시스템을 구성하였다.

카메라는 1/3inch CCD sensor가 적용된 카메라를 사용하였으 며, 렌즈는 지름이 $125 \mu \mathrm{m}$ 인 광파이버를 검출하기 위하여 15 배율 렌즈를 사용하였다. 이때 카메라의 FOV (Field of View)는 약 $320 \times 240 \mu \mathrm{m}$ 이다. 그리고 본 검사 시스템에 적용된 고배율 렌즈 때문에 집중광선을 사용하였다.

카메라의 $\mathrm{FOV}$ 는 약 $320 \times 240 \mu \mathrm{m}$ 으로 페롤에 삽입된 광섬유 단면 을 한 개의 제품만 검사 가능하다. 해당 연구에서는 연속적으 로 다량의 제품을 검사하기 위하여 Fig. 3 과 같이 $8 \times 8$ 배열의 정렬 지그를 적용하였으며, 이 사이의 간격은 약 $12 \mathrm{~mm}$ 이다. $\mathrm{X}-\mathrm{Y}$ 축 직교 로봇이 1 행을 $12 \mathrm{~mm}$ 간격으로 7번 이동하여 1 열부 


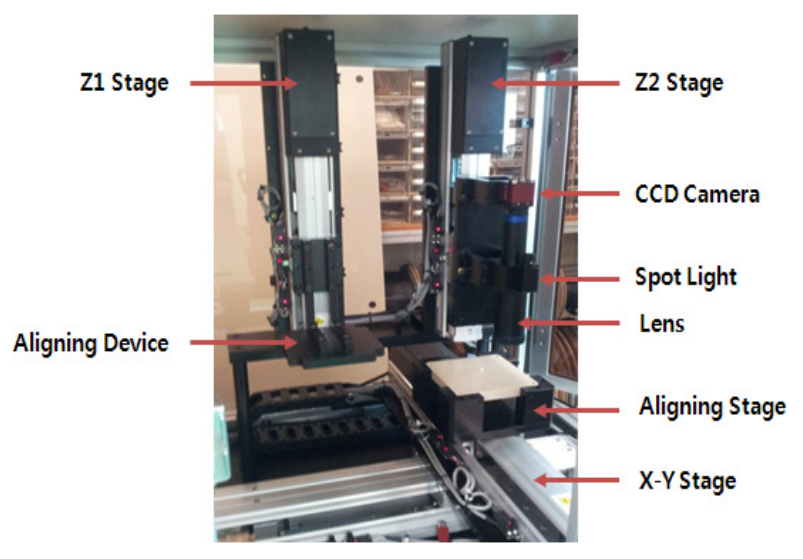

Fig. 2 Automatic aligning and inspection system

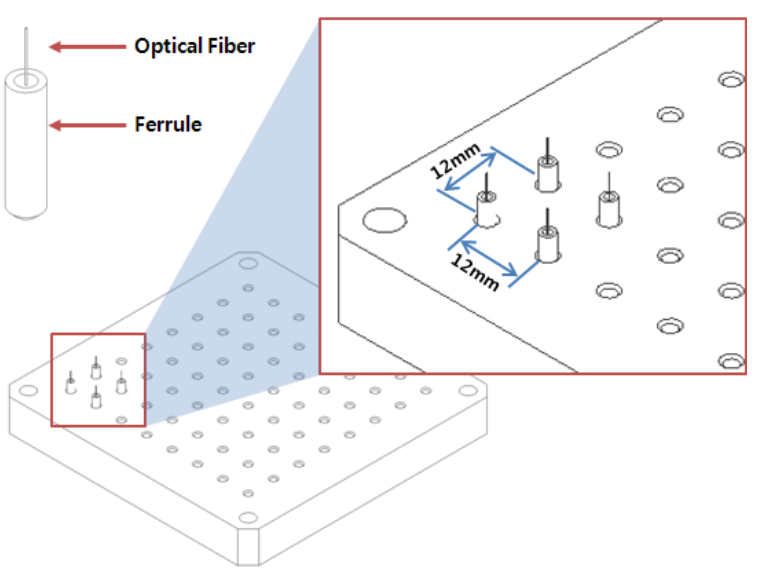

Fig. 3 The definition of femule and alignment jig

Table 1 Hardware specification

\begin{tabular}{|c|c|c|}
\hline Items & Specification & Maker \\
\hline Camera & $\begin{array}{l}\text { Model : Guppy F-80 } \\
\text { Resolution : } 1024 * 768 \\
\text { Capture Speed : } 30 \mathrm{fps} \\
\text { Sensor : Sony ICX204 } \\
\text { Senser type : } 1 / 3\end{array}$ & ALLIED \\
\hline Lens & $\begin{array}{r}\text { Model : } \text { SOD - } 10 \mathrm{X} \\
\text { SOD - } 1.5 \mathrm{X}\end{array}$ & MORITEX \\
\hline $\begin{array}{l}\text { Spot } \\
\text { Light }\end{array}$ & Model : TLC-3WR & Teknix \\
\hline $\begin{array}{l}\text { Back } \\
\text { Light }\end{array}$ & Model : MDBC-CR100 & MORITEX \\
\hline $\mathrm{PC}$ & $\begin{array}{l}\text { CPU : Intel Dual core E6500 } \\
\text { Memory : DDR2 2GB }\end{array}$ & ADVANTECH \\
\hline Board & $\begin{array}{l}\text { DAQ board : NI PCI } 6519 \\
\text { Motion board : NI PCI } 7390 \\
\text { Image Acquisition board : PCI } 1394\end{array}$ & NI \\
\hline Robot & $\begin{array}{l}\text { Motor : Servo Moter } \\
\text { Type : Ball Screw } \\
\text { Precision : } \pm 3 \mu \mathrm{m}\end{array}$ & SANYO \\
\hline
\end{tabular}

터 8열까지 검사하고, 2행 1열로 다시 이동한다. 이를 반복적으로 구동하여 총 64 개의 광파이버를 검사하도록 시스템을 개발하였다. 즉, 기존에 한 개씩 진행하던 수작업 검사 대비 대기 시간을 약 $80 \%$ 이상 감소 시켰다. 정렬지그에 광섬유를 삽입 시에 수작업으 로 진행하므로 광섬유가 작업도중 깨지는 일이 많이 발생하였다. 이 문제를 해결하기 위하여 사이 간격을 약 $12 \mathrm{~mm}$ 두고 배열 하여 작업자의 작업속도에 영향을 주지 않는 기준으로 했다. 광파이버 자동 정렬 및 검사 시스템에 구성된 기구부의 사양은 Table 1과 같다. 직교 로봇은 지름이 $125 \mu \mathrm{m}$ 인 광파이버의 이미지를 획득하 기 위하여 정밀 제어가 필요하였으며, 볼스크류 타입의 서보모터가 적용된 반복정밀도 $\pm 3 \mu \mathrm{m}$ 을 갖는 직교 로봇을 사용하였다. 오토 포커싱과 자동 정렬 장치에도 같은 반복정밀도를 갖는 로봇을 사용 하였다.

\section{3 자동 정렬 및 검사 프로그램 개발}

\subsubsection{LabVIEW를 이용한 검사 프로그램 개발}

자동 정렬, 검사 UI (User Interface) 및 제어 프로그램은 비전 모션 검사 자동화 라인에 적용된 사례가 많고 효율성이 검증된 컴 퓨터 기반의 제어 계측 전문 언어인 NI (National Instruments) 사의 랩뷰(LabVIEW $\left.{ }^{\mathrm{TM}}\right)$ 를 사용하였다 ${ }^{[13-14]}$. NI - Motion을 이용 하여 모터를 제어하고, NI - Vision을 이용하여 광파이버 검사를 진행 하였다. 또한, $\mathrm{NI}-\mathrm{DAQ}$ 를 이용하여 기본 스위치 및 $\mathrm{DI} / \mathrm{O}$

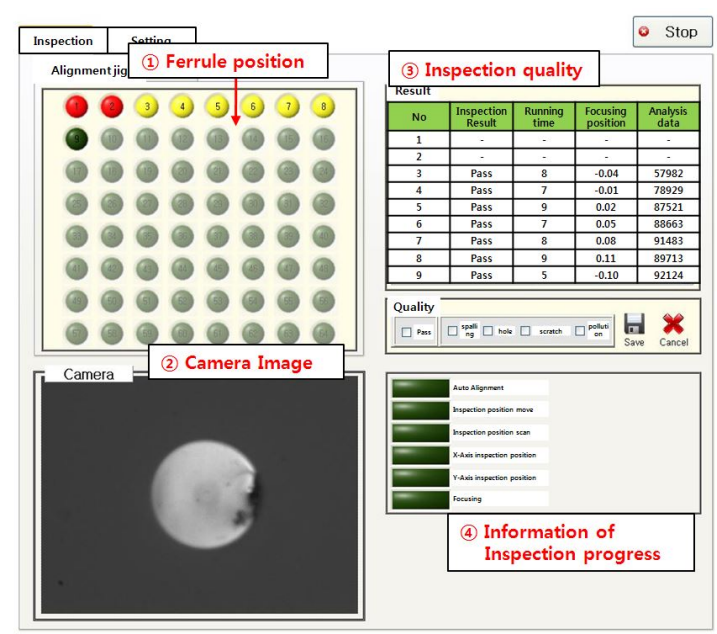

Fig. 4 Program UI of automatic alignment and inspection

Table 2 Software Information

\begin{tabular}{c|c|c}
\hline \hline Items & Software & Maker \\
\hline \multirow{3}{*}{ Program } & LabVIEW 2010 & \\
& NI-Motion & NI \\
& NI-Vision & \\
& NI-DAQ & \\
\hline
\end{tabular}


Data를 수집하여 시스템을 구축하였다. 랩뷰를 이용하여 모션과 비전에 대한 알고리즘을 개발 하였으며, 이는 하나의 제어 프로그 램에서 모션과 비전에 대한 알고리즘 구축으로 시스템을 간소화 하였다.

본 프로그램의 Main UI (User interface)는 현장에서 작업자가 검사가 진행되고 있는 제품 번호와, 제품의 단면 이미지를 실시간 으로 확인 하고 결과를 저장할 수 있도록 개발되었다. 개발된 UI를 통하여 검사 결과에 따른 품질 정보뿐만 아니라, 필요에 따라 불량 제품을 바로 제거 할 수 있는 효과를 얻을 수 있다. 검사 장비는 물리적인 시작버튼에 의하여 동작하며 DI/O Board에서 신호를 수 집하여 프로그램에서 시작 트리거 신호를 받는다.

\subsection{2 자동 정렬 및 검사 프로그램 Flow Chart}

자동 정렬 및 검사 프로그램의 Flow Chart는 Fig. 5와 같다. 시 작 버튼을 누르면 정렬 지그에 삽입된 페롤과 광파이버를 설정된 일정한 높이로 맞추기 위하여 광섬유 높이 조절부로 이동 후 광섬 유 높이 정렬을 진행한다. 이 과정은 제품의 길이 조절 역할도 있으 며, 카메라를 이용한 검사를 진행할 때 $\mathrm{WD}$ 와 오토포커싱 기능을 사용하기 위하여 검사단면의 높이를 일정하게 만들어 카메라로부 터 모든 광파이버까지의 $\mathrm{WD}$ 를 고정 시킨다. 광섬유 단면 검사에 서는 $8 \times 8$ 배열된 정렬 지그에 페롤의 유무를 확인한다. 이 과정은 페롤이 없는 부분에 광섬유 검색을 진행하여 공정시간(Tact Time) 이 증가되는 것을 최소화 하는 기능이다. 정렬 지그에 페롤이 들어 있으면 페롤 가운데의 광파이버를 검출 알고리즘을 통하여 찾고, 이미지를 획득하여 단면 상태를 영상처리를 통한 검토 후 다음 Step으로 이동 한다.

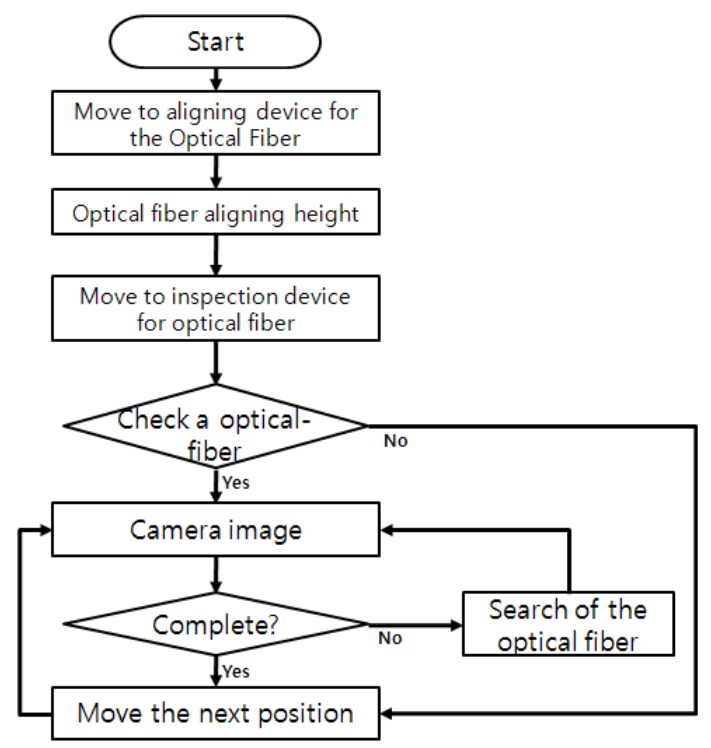

Fig. 5 Flow chart of automatic alignment and inspection program

\section{4 검사 프로그램 알고리즘}

\subsection{1이미지 수집 오토포커싱 알고리즘}

수집된 이미지를 이용하여 영상처리를 하므로 해당 연구에서 오 토포커싱은 중요한 부분이다. 사용되는 렌즈는 고정 $\mathrm{WD}$ 에서 포커 싱이 가능하므로 $0.01 \mathrm{~mm}$ 이내로 초점을 포커싱 해야 한다. 광파 이버 정렬에 의한 오차, X-Y Stage조립에 의한 수평 오차 등을 고려하여 오토포커싱 알고리즘을 적용하였다. 오토포커싱의 알고 리즘은 획득된 이미지 픽셀 값에 대한 표준편차를 이용하였다. 표 준편차 계산식은 식 (1)과 같다.

$$
\begin{aligned}
& \sigma=\sqrt{\frac{\sum_{k=1}^{n}\left(x_{k}-m\right)^{2}}{n}}=\sqrt{\frac{\sum_{k=1}^{n} x_{k}^{2}}{n}-m^{2}} \\
& m=\text { 관측값, } x_{1}, x_{2}, \cdots, x_{n} \text { 의 평균값, } n=\text { 측정수 }
\end{aligned}
$$

본 연구에서 획득한 영상 이미지는 광파이버부분과 여백 부분의 명암차이가 크기 때문에 모든 픽셀의 Gray scale값 평균과 표준편 차를 이용하여 연산 가능하다. 프로그램에 적용된 랩뷰의 포커싱 블록 다이어그램은 Fig. 6과 같다.

랩뷰의 포커싱 알고리즘은 카메라와 렌즈가 부착된 $\mathrm{Z}_{2}$ Axis를 $\mathrm{d}_{1}$ 에서 $\mathrm{d}_{2}$ 까지 이동하면서 Fig. 7과 같이 거리 - 표준편차 그래프 로 만든다. 표준편차가 가장 높은 위치인 $\mathrm{d}_{\mathrm{p}}$ 로 $\mathrm{Z}_{2}$ Axis를 이동하여 최상의 초점 값을 갖는 이미지를 획득한다 ${ }^{[11]}$.

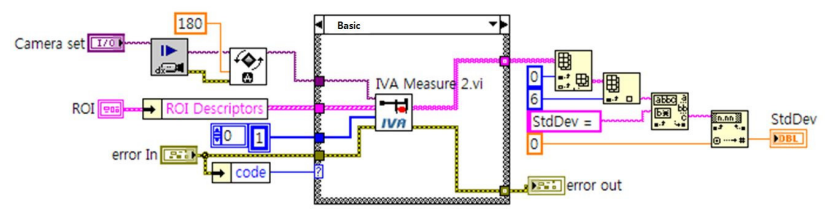

Fig. 6 Focusing Block diagram of LabVIEW

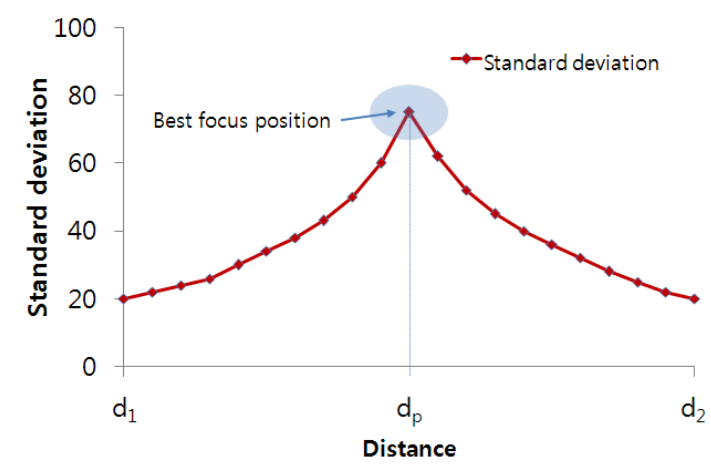

Fig. 7 Distance-Standard deviation graph 


\subsection{2 광파이버 검출 알고리즘}

본 연구에서 광파이버 검출 알고리즘은 기구적인 오차를 소프트 웨어를 이용하여 보안하기 위한 알고리즘이다. X-Y Stage와 정렬 지그의 조립, 가공 오차 그리고 페롤의 삽입 오차가 물리적으로 존 재 할 수밖에 없다. 광파이버의 지름은 약 $125 \mu \mathrm{m}$ 이므로 시스템의 조립 및 가공 오차를 소프트웨어를 이용하여 보안해야 한다. 즉, $\mathrm{FOV}$ 가 약 $320 \times 240 \mu \mathrm{m}$ 이므로 S-Y Stage를 일정 공간을 이동 하면서 이미지를 수집하고, 수집된 이미지를 이용하여 페롤에 삽입 된 광파이버를 검출한다. Fig. 8 은 검출 알고리즘의 개략도 이다.

\subsection{3 페롤 검출 알고리즘}

본 연구의 페롤 검출 알고리즘은 정렬지그에 페롤이 삽입되어 있지만 페롤에 광파이버가 없는 경우에는, 광파이버 검출 알고리즘 을 진행하면 공정시간이 증가 하므로, 이를 사전에 차단하기 위하 여 페롤 유무를 먼저 검사한다. 페롤 검출은 Fig. 9와 같이 수집된 이미지의 히스토그램을 이용하여 확인 하였다.

집중광선과 15 배율의 렌즈를 사용하므로, 페롤이 있는 경우와 없는 경우 $\mathrm{WD}$ 가 달라지므로 조명에 의하여 반사되는 위치가 달라 진다. 즉, 페롤이 있을 경우에는 페롤에 반사되는 빛의 양이 많아서 밝은 이미지가 수집되고 페롤이 없을 경우에는 반사되는 빛의 양이

\begin{tabular}{|c|c|c|c|c|}
\hline 11 & 12 & 13 & 14 & 15 \\
\hline 10 & 1 & 2 & 3 & 16 \\
\hline 9 & 8 & $\begin{array}{l}\text { Starting } \\
\text { point }\end{array}$ & 4 & 17 \\
\hline 24 & 7 & 6 & 5 & 18 \\
\hline 23 & 22 & 21 & 20 & 19 \\
\hline
\end{tabular}

Fig. 8 Detecting algorithm of optical fiber

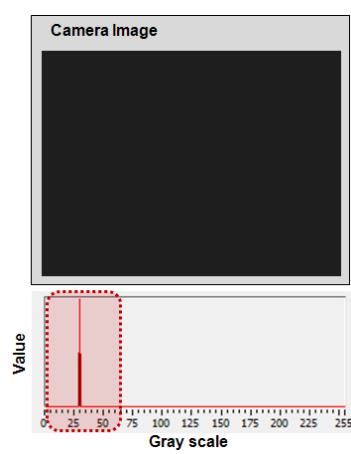

(a) Ferrule no

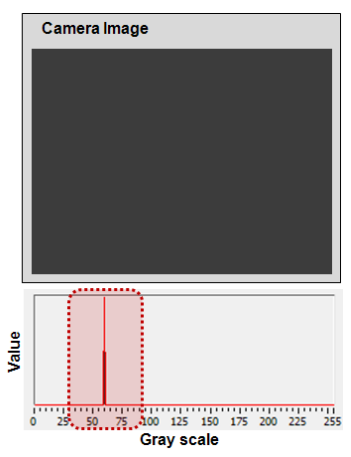

(b) In ferrule
Fig. 9 Detecting algorithm of ferrule
적어 어두운 이미지가 수집된다. 페롤이 없는 경우는 Gray scale 값의 평균이 약 27 Value이고, 페롤이 존재하는 경우는 Gray scale 값의 평균이 약 60 Value 정도 이다. 임계값을 약 50 Value 로 설정하여 페롤 검출 알고리즘을 적용하였으며, 이로 인하여 정 렬 지그에 페롤이 없는 경우에 광파이버 검출 알고리즘을 적용하지 않는다.

\subsection{4 양품 \& 불량 판단을 위한 검사 알고리즘}

카메라로부터 수집한 광파이버 단면의 불량 여부를 검사하기 위 한 알고리즘이다. 카메라로부터 수집된 이미지는 $8 \mathrm{bit}$ 이미지 이 므로 검사를 하기 위하여 우선 이진화된 이미지로 변환해야 한다. 이를 위한 알고리즘은 Fig. 10과 같이 8 bit 이미지의 Gray scale 의 임계값을 설정하여 이진화 시킨다.

이진화된 이미지에서 광파이버가 손상된 부분과 전에 여백은 흰 색으로 보인다. 검사를 하기 위해서 손상된 부분만 따로 추출하여 Fig. 11 과 같이 광파이버의 부분을 뺀 나머지 부분을 제거 하는 알고리즘을 구성하였다. 이미지 빼기 연산은 식 (2)와 같이 픽셀 단위 빼기 알고리즘을 이용하였다 ${ }^{[12-13]}$.
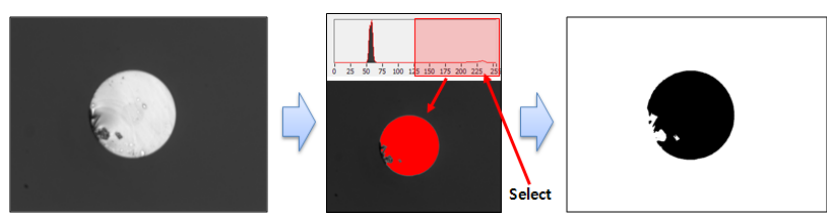

Fig. 10 Image binary

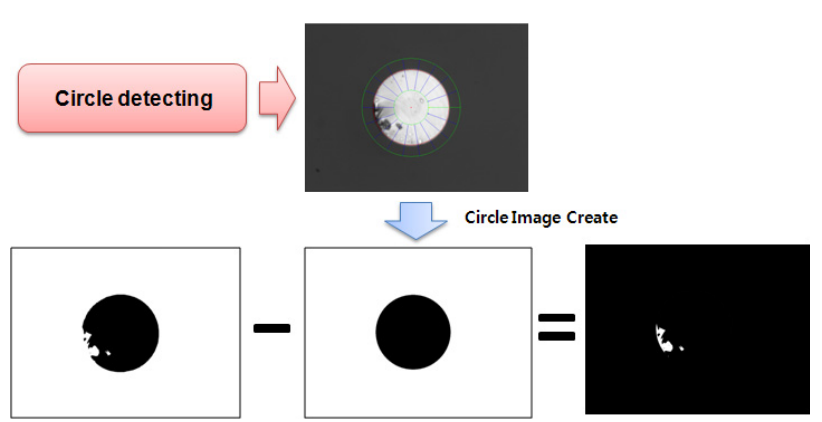

Fig. 11 Subtraction operation of the image

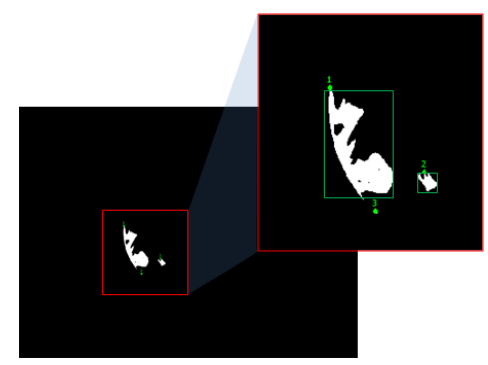

Fig. 12 Particle Analysis of the image 


$$
\text { Image Output }(x, y)
$$

$$
=\operatorname{Image}_{1}(x, y)-\operatorname{Image}_{2}(x, y)
$$

결과 이미지에 랩뷰의 Particle Analysis 알고리즘을 이용하여 Fig. 12와 같이 손상된 부분의 정보를 추출한다. 추출되는 정보는 손상된 부분의 위치, 개수, 크기의 정보를 이용하여 양 불량 여부를 판단한다.

\section{3. 실 험}

\section{1 광파이버 정렬}

본 연구에서 개발된 시스템의 성능을 평가하기 위하여 광파이버 페롤에 삽입된 광파이버의 자동 정렬 실험을 하였다. Fig. 13 은 정렬되지 않은 광파이버를 본 연구에서 개발된 시스템에 적용하여 정렬 후의 모습이다. 정렬을 10 회 반복 테스트하여 자동 정렬 장치 에 대한 성능을 평가 하고자 정렬 시간과 불량률을 분석 하였다.

자동 정렬은 64 개의 광파이버를 한번에 정렬한다. 성능 평가를 하기 위하여 Fig. 14와 같이 분석 하였다. 수작업과 자동 정렬 모두 64개를 $1 \mathrm{Set}$ 로 10회 실험하였으며, 수작업의 경우는 페롤 삽입, 절단 시간 합의 평균은 약 $1243.85 \mathrm{sec}$ 이며, 자동 정렬의 경우는 페롤 삽입 \& 자동 정렬 합의 평균은 약 $934.20 \mathrm{sec}$ 로 실험 결과를 보였다. 실험 결과로 보아 수작업에 비하여 자동 정렬을 할 때 소요 시간이 약 $24.89 \%$ 단축 되는 것을 확인 하였으며, 광파이버 절단 또는 정렬 중에 발생하는 광파이버 깨짐 현상에 의한 불량은 각 Sample당 10 회 반복 정렬하여 광파이버가 깨지는 확률의 평균 값 이며, 수작업 시 약 $9.8 \%$, 자동 정렬 시 약 $1.9 \%$ 발생률을 보였다. 즉, 수작업 대비 자동 정렬을 이용할 경우 기존대비 약 $80.95 \%$ 의 불량률 감소 효과를 보았다.

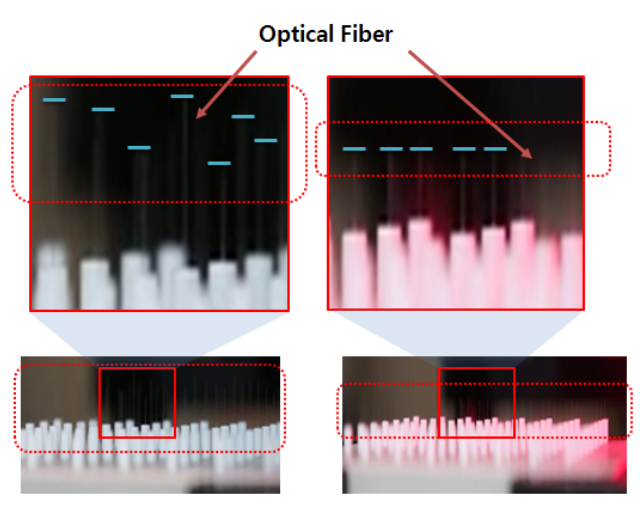

(a) Before

(b) After

Fig. 13 Automatic aligning test

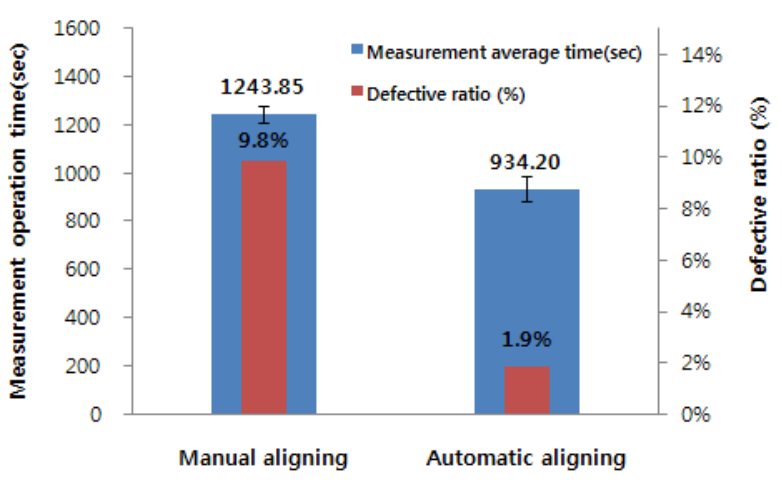

Fig. 14 A comparison of the operation time in manual aligning and automatic aligning

\section{2 광파이버 단면 검사}

본 연구를 통하여 개발된 시스템의 광파이버 검사 성능을 평가하 기 위하여 페롤에 광파이버가 삽입된 8개의 Sample을 준비 하였 으며, 한 종류의 제품이며, 각 Sample당 10 회 반복 실험을 통하여

Table 3 Inspection result of optical fiber cross section

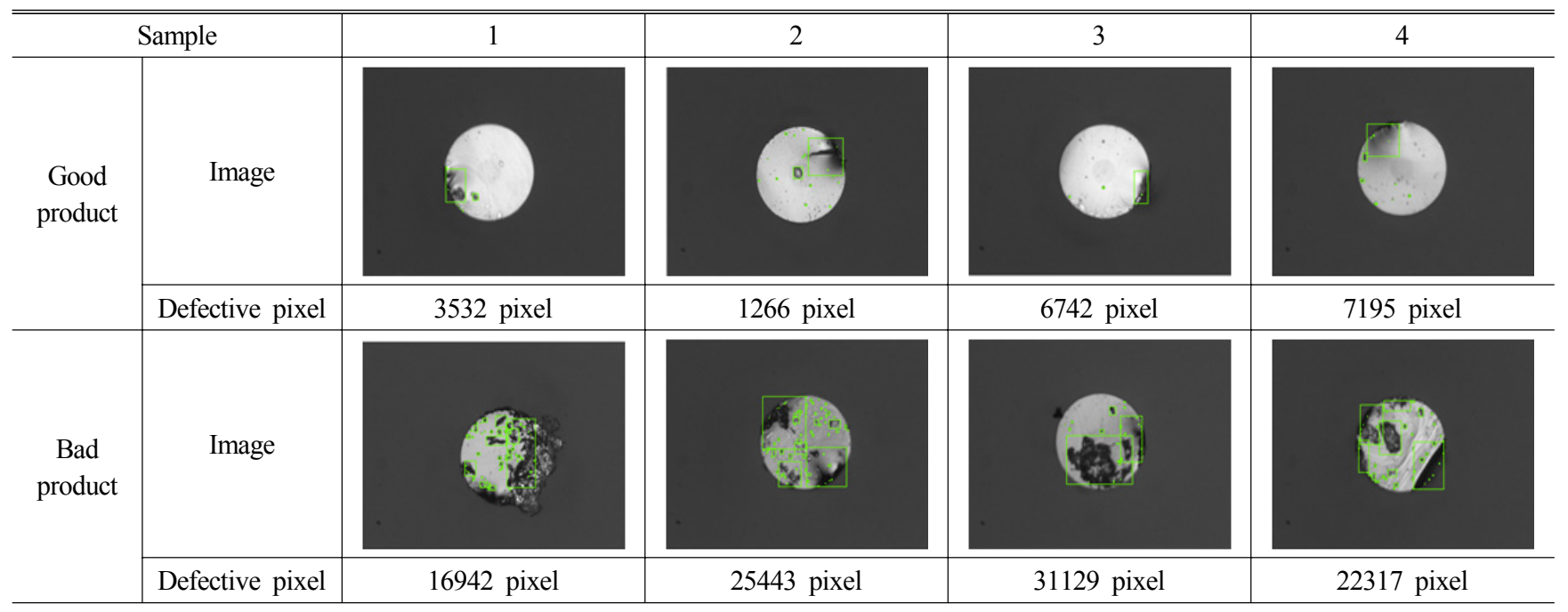


기존 수작업 대비 자동 검사 시간을 비교 분석 하였다. Table 3은 신뢰성 평가를 위하여 적용 Sample을 양품 4 개와 불량 4 개로 분류 하여 같은 조건으로 실험 진행 하여, 비교 분석한 광파이버의 단면 검사 결과이다. 불량 부분의 pixel 개수의 평균 분석은 Fig. 15 와 같으며, 양품 제품의 경우 검출되는 불량부분 픽셀 수의 평균이 약 4683.75 pixel이고, 불량 제품의 경우 23957.75 pixel으로 불량 제품의 불량 픽셀이 양품 제품의 불량 픽셀에 비하여 약 $412 \%$ 이상 높은 것을 보였다.

또한, Fig. 16 과 같이, 검사 시간에 대한 비교에서는 기존 수작업 으로 64개의 제품 검사를 진행 하였을 때는 평균으로 약 $960.43 \mathrm{sec}$ 가 소요 되었고, 자동 검사 진행 하였을 때는 평균으로 약 643.83 $\sec$ 가 소요 되어, 약 $33.9 \%$ 의 시간단축을 보였다. 즉, 해당 결과를 통하여 본 연구의 광파이버 불량 검사에 대한 신뢰성이 높은 것으 로 판단 할 수 있다.

본 해당 연구를 통하여 개발된 시스템은 기존에 페롤에 삽입된 광파이버를 절단하는 수작업을 자동으로 대체하여, 기존 수작업 절 단 시에 발생하는 불량률을 기존 약 $10 \%$ 에서 약 $2 \%$ 내외로 감소시 키는 경향을 보였으며, 광파이버 자동 정렬과 검사 시간 단축으로 기존 대비 약 $28 \%$ 의 공정시간을 감소시키는 결과를 보였다.

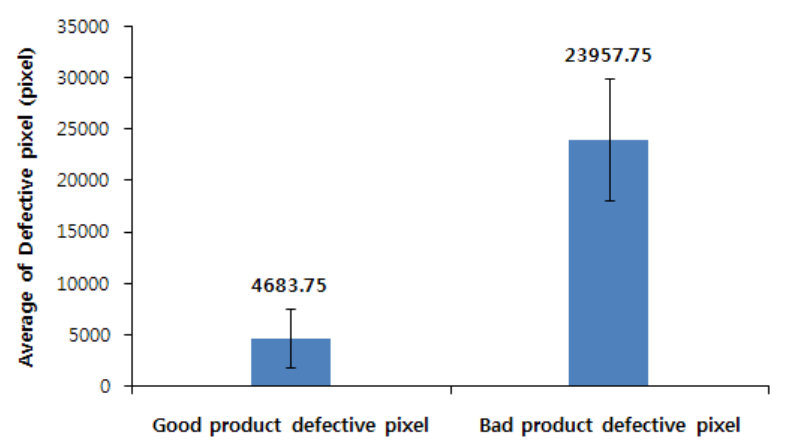

Fig. 15 A comparison of the defective pixel in good product and bad product

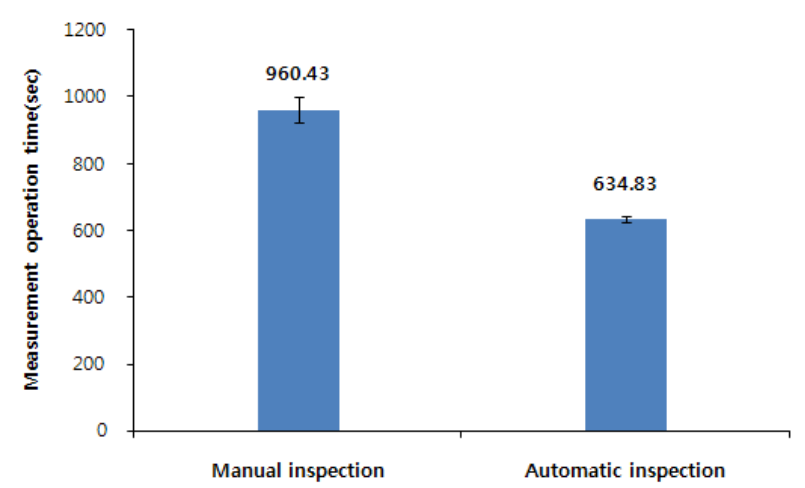

Fig. 16 A comparison of manual inspection time and automatic inspection time

\section{4. 결 론}

본 연구는 현장조립형 커넥터를 생산하기 위한 광파이버가 삽입 된 페롤의 높이를 정렬하고 단면 상태를 검사하여 광파이버의 양불 판단을 하는 시스템을 개발하였다. 재료비 차원에서는 페롤 재사용 가능으로 재료비를 절약하는 효과가 있을 것으로 예상되며, 작업자 의 주관적인 판단에 의한 양불 판단에 비하여 좀 더 신뢰성 있는 품질 관리가 될 것으로 보인다. 본 연구를 통한 시스템 개발로 향 후 에는 연마 처리된 페롤의 광파이버 검사 부분에도 적용이 가능 할 것으로 예상된다.

\section{후 기}

이 연구는 2012년도 중소기업 제조환경녹색화 기술개발 사업 지 원으로 수행되었습니다(과제번호: S2067015).

\section{References}

[1] Kim, B. G., Choi, Y. G., Oh, H. S., Park, T. D., 2005, Field Assembly Connector for Optical Cable Splicing, Proceedings of Korea Institute of Information \& Telecommunication Facilities Engineering, 170-173.

[2] Jung, J. H., 2007, Research about Optical Signal Detector and FAOC(Filed Assembly Optical Connector) used in FTTH, Master Thesis, Honam University, Republic of Korea.

[3] Han, S. H., Jang, G. J., Yoon, K. J., Cha, J. H., Roh, K. S., Kweon, I. S., 2001, Recent Developments in Machine Vision Research, Journal of the Korean Society of Precision Engineering, 18:3 23-34.

[4] Kim, M. S., Chio, K. S., Shim, B. K., Jung, S. W., Won, J. D., Han, S. H., 2013, A Technology of Automatic Inspection for Semiconductor Good and Faulty based on Robot Vision, Proceedings of the Korean Society of Manufacturing Technology Engineers Autumn Conference, 277.

[5] Jain, R., Katsuri, R., Schunck, B. G., 1995, Machine Vision, McGraw Hill, USA.

[6] Tucit, J. D., Jung, H., Jang, B. C., 2007, Development of an Inspection System for Car Seat Bottom Cushion Frame using Machine Vision, Proceedings of the Korean Academia-industrial Cooperation Society Autumn Conference, 313-314.

[7] Kim, J. Y., Cho, H. S., 2005, Vision based Part Shape and Misalignment Measurement in Cylindrical Peg in Hole Tasks, Journal of the Control Automation and Systems Engineering, 11:7 615-620. 
[8] Park, J. S., Yun, D. H., Jeong, C. S., Kim, Y. S., Yang, S. Y., 2010, Development of Machine Vision System for Inspection of Screw/Bolt Shape, Proceedings of the Korean Society of Mechanical Engineers Autumn Conference, 1632-1637.

[9] Kim, Y. S., Yang, S. Y., 2010, Development of the Sorting Inspection System for Screw/Bolt using a Slant Method, Journal of the Korean Society of Manufacturing Technology Engineers, 19:5 698-704.

[10] Choi, Y. J., Chung, S. C., 2006, Monitoring of Micro Drill Wear by using the Machine Vision System, Journal of the Korean Society of Mechanical Engineers, 30:6 713-721.

[11] Xiao, T., Pierre, L., Yu, X., 2000, An Auto-Focusing Method in a Microscopic Tested for Optical Discs, Journal of Research of the
National Institute of Standards and Technology, 105:4 565-569.

[12] Jang, D. H., 2003, Digital Image Processing using Visual C++, Ymedia, Korea.

[13] Lee, J. H., Park, C. H., Seo, Y. S., Lee, H. S., Kim, H. J., 2013, Development of Vehicle Sealing Inspection System using Geometry Matching Method, Journal of the Korean Society of Manufacturing Technology Engineers, 22:1 150-155.

[14] Yun, S. H., Kim, H. J., Kim, S. G., 2008, Development of Stereo Vision based Welding Quality Inspection System for RV Sinking Seat, Transactions of the Korean Society of Machine Tool Engineers, 17:3 71-77. 